\title{
Distinctive Neuronal Networks and Biochemical Pathways for Appetitive and Aversive Memory in Drosophila Larvae
}

\author{
Ken Honjo and Katsuo Furukubo-Tokunaga \\ Graduate School of Life and Environmental Sciences, University of Tsukuba, Tsukuba, Ibaraki 305-8572, Japan
}

\begin{abstract}
Associative strength between conditioned stimulus (CS) and unconditioned stimulus (US) is thought to determine learning efficacy in classical conditioning. Elucidation of the neuronal mechanism that underlies the association between CS and US in the brain is thus critical to understand the principle of memory formation. With a simple brain organization, the Drosophila larva provides an attractive model system to investigate learning at the neurocircuitry level. Previously, we described a single-odor paradigm for larval associative learning using sucrose as a reward, and showed that larval appetitive memory lasts longer than $2 \mathrm{~h}$. In this work, we describe behavioral and genetic characterization of larval aversive olfactory memory formed in our paradigm, and compare its stability and neurocircuitry with those of appetitive memory. Despite identical training paradigms, larval olfactory memory formed with quinine or $\mathrm{NaCl}$ is shortlived to be lost in $20 \mathrm{~min}$. As with appetitive memory, larval aversive memory produced in this paradigm depends on intact cAMP signaling, but neither mutation of amnesiac nor suppression of CREB activity affects its kinetics. Neurocircuitry analyses suggest that aversive memory is stored before the presynaptic termini of the larval mushroom body neurons as is the case with appetitive memory. However, synaptic output of octopaminergic and dopaminergic neurons, which exhibit distinctive innervation patterns on the larval mushroom body and antennal lobe, is differentially required for the acquisition of appetitive and aversive memory, respectively. These results as a whole suggest that the genetically programmed memory circuitries might provide predisposition in the efficacy of inducing longer-lived memory components in associative learning.
\end{abstract}

Key words: dopamine; octopamine; shibire; dunce; rutabaga; mushroom body

\section{Introduction}

In Pavlovian conditioning, animals learn association between a conditioned stimulus (CS) and an unconditioned stimulus (US) through training. Because associative strength between CS and US is thought to determine learning efficacy, elucidation of the neuronal mechanism that underlies CS-US association in the brain is critical to understand the principle of memory formation. In the past decades, studies in Drosophila have uncovered seminal aspects of associative memory including signaling molecules and memory phases (Davis, 2005; Margulies et al., 2005; Keene and Waddell, 2007). Anatomically, mushroom bodies (MBs) have been characterized as centers for olfactory memory in the fly brain (Heisenberg, 2003). MBs receive olfactory information from the antennal lobe $(\mathrm{AL})$ via the projection neurons. During memory formation, MBs also receive recurrent signals from dorsal paired medial neurons, the activity of which is essential to induce middle-term memory (MTM) with both aversive

Received March 27, 2008; revised Dec. 15, 2008; accepted Dec. 15, 2008.

This work was supported by a Grant-in-Aid for Japan Society for the Promotion of Science Fellows to K.H. and Grants-in-Aid for Scientific Research from the Ministry of Education, Culture, Sport, Science, and Technology of Japan to K.F.-T. We are grateful to Drs. Minoru Saitoe and Masatomo Kobayashi for fly stocks and helpful suggestions. We are also grateful to Takahisa Shimoyama, Tetsuya Ando, and Asami Tanaka for helpful assistance. We thank Drs. T. Kitamoto, C. O'Kane, M. Schwaerzel, and M. Heisenberg for fly stocks. We also thank the Bloomington Stock Center and Developmental Studies Hybridoma Bank for fly stocks and antibodies.

Correspondence should be addressed to Katsuo Furukubo-Tokunaga, Graduate School of Life and Environmental Sciences, University of Tsukuba, Tsukuba, Ibaraki 305-8572, Japan. E-mail: tokunaga@sakura.cc.tsukuba.ac.jp.

DOI:10.1523/JNEUROSCI.1315-08.2009

Copyright $\odot 2009$ Society for Neuroscience $\quad$ 0270-6474/09/290852-11\$15.00/0 and appetitive US cues (Waddell et al., 2000; Keene et al., 2004, 2006; Yu et al., 2005; Krashes et al., 2007). In addition, pharmacological and molecular studies in honeybees (Hammer and Menzel, 1998) and fruit flies (Yu et al., 2004; Thum et al., 2007) suggest that AL functions as another neural structure involved in memory formation.

Studies in Drosophila have also provided insights into differential properties of appetitive and aversive memory. In a classic study, Tempel et al. (1983) suggested different memory kinetics of electric shock and sugar-reward memories. As for neural modulators, octopamine (OA) and dopamine (DA) have differential roles in acquisition of appetitive and aversive memory, respectively (Schwaerzel et al., 2003; Schroll et al., 2006), although it is also shown that mutations of the $\mathrm{D}_{1}-\mathrm{DA}$ receptor (dDA1) significantly suppress aversive olfactory learning, and moderately impair sugar-mediated learning (Kim et al., 2007). In addition, an overlapping set of $\mathrm{MB}$ neurons might be involved in retrieval of both appetitive and aversive memory (Schwaerzel et al., 2003; Krashes et al., 2007; Thum et al., 2007).

To dissect the neurocircuitry of olfactory memory, the Drosophila larva provides an excellent model system. The larval brain is much simpler than the adult brain, and the basic design of its olfactory system is highly straightforward without redundancy (Ramaekers et al., 2005; Gerber and Stocker, 2007; Vosshall and Stocker, 2007). We have previously described that a sugar-reward training of Drosophila larvae produce olfactory memory that is retained beyond $120 \mathrm{~min}$ and depends on both amnesiac (amn) 
and cAMP response element-binding protein (CREB) (Honjo and Furukubo-Tokunaga, 2005).

In this work, we have extended our larval study using aversive reinforcers. We show that larval memory formed with quinine hemisulfate $(\mathrm{QH})$ is short-lived and suggest that it is stored before the synaptic termini of $\mathrm{MB}$. We also show that synaptic output of larval OA and DA neurons is differentially required for the acquisition of appetitive and aversive memory, respectively. These monoaminergic pathways exhibit discrete convergence patterns with the odor CS pathway in the larval brain, suggesting the importance of genetically programmed circuits in efficient induction of longer-lived memory components in associative learning.

\section{Materials and Methods}

Fly stocks. The following fly stocks were used: wild-type Canton-S; shortterm memory (STM) mutants rutabaga $(\text { rut })^{1}$ (Livingstone et al., 1984) and dunce $(d n c)^{1}$ (Dudai et al., 1976); MTM mutant $a m n^{28 \mathrm{~A}}$ (DeZazzo et al., 1999); $h s-d C R E B 2-b$ transgenic fly (line 17-2) (Yin et al., 1994); UASshibire $^{\text {ts1 }}$ inserted on chromosome III (Kitamoto, 2001); MB-GAL4 enhancer trap line OK301 (Connolly et al., 1996; Honjo and FurukuboTokunaga, 2005) and $201 Y$ (Yang et al., 1995); TH-GAL4 (Friggi-Grelin et al., 2003); TDC2-GAL4 (Cole et al., 2005); and UAS-mCD8::GFP (Lee and Luo, 1999). Stocks were kept at $25^{\circ} \mathrm{C}$ on a standard food as described previously (Honjo and Furukubo-Tokunaga, 2005).

Larval conditioning experiments. Larval conditioning experiments were performed as described previously (Honjo and FurukuboTokunaga, 2005). Larvae were raised with standard food without propionic acid. Staged early third instar larvae (72-76 h after egg laying) were used for all experiments. Unless otherwise noted, larval behavioral experiments were performed at $25^{\circ} \mathrm{C}$. For training, larvae were placed on the surface of a $2.5 \%$ agar plate (diameter $85 \mathrm{~mm}$ ), on which $1 \mathrm{ml}$ reinforcers were spread shortly before experiments. Undiluted odor $(10 \mu \mathrm{l})$, linalool (LIN) (Nacalai), or pentyl acetate (PA) (Nacalai) was spotted on a filter disk (55 $\mathrm{mm}$ in diameter) placed on the inside of the lid, and larvae were exposed to the odor for $30 \mathrm{~min}$ in conjunction with the reinforcer solution. The reinforcers used were $1 \mathrm{~m}$ sucrose (SUC) (Nacalai), $0.1 \%$ $\mathrm{QH}$ (Sigma), or $1 \mathrm{~m} \mathrm{NaCl}$ (Wako). Distilled water (DW) was used for the control. Typically, several hundreds animals are placed on a plate and conditioned en masse. During conditioning, larvae crawl around over the wet gel surface taking up the US substance as liquid. The majority of the animals ingested the reinforcer during the $30 \mathrm{~min}$ training $(94 \%$ for $1 \mathrm{M}$ SUC, $90 \%$ for DW, and $88 \%$ for $0.1 \%$ QH, by uptake tests with $0.2 \mathrm{mg} / \mathrm{ml}$ Acid Red 52). In the temporal dissociation test, animals were successively exposed to odor and reinforcer for $30 \mathrm{~min}$ each as described previously (Honjo and Furukubo-Tokunaga, 2005).

Larval olfactory response was measured by a single odor preference test adapted from Heimbeck et al. (1999). After associative training, larvae were harvested with DW, gently rinsed three times with DW in a 100 $\mathrm{ml}$ beaker to remove residual odorant and reinforcer, and transferred onto test agar plates. For each test, the Response Index (RI) was calculated as RI $=$ (the numbers of animals in odor area minus the number of animals in control area)/(total number of animals counted). For an indicator of memory performance, $\Delta \mathrm{RI}$ was calculated as RI (odor/reinforcer) minus RI (odor/DW). For memory retention tests, larvae were trained as above, then transferred to another agar plate and kept for the indicated time before the memory test.

The experiments with UAS-shibire ${ }^{\text {ts } 1}$ were performed in temperaturecontrolled rooms adjusted at the permissive $\left(25^{\circ} \mathrm{C}\right)$ or the restrictive $\left(30^{\circ} \mathrm{C}\right.$ or $\left.31^{\circ} \mathrm{C}\right)$ temperatures. All instruments and reagents were stabilized to the indicated temperature before experiments. For temperature shift, larvae trained in the first temperature room were moved to the secondary temperature room. The plates were kept in a foam-polystyrene insulator box during the transfer between the different temperature rooms.

Olfactory and gustatory response tests. Larval olfactory and gustatory responses were determined as described previously (Honjo and
Furukubo-Tokunaga, 2005). Fifty to 100 larvae were used per single experiment. RI was determined after $3 \mathrm{~min}$. Gustatory response was measured using plastic plates with a median separator ( $85 \mathrm{~mm}$, Eiken). The control half was filled with $0.5 \%$ agar and the test half with $0.5 \%$ agar containing $1 \mathrm{~m}$ sucrose or $0.1 \% \mathrm{QH}$. Plates were solidified for $2 \mathrm{~h}$ at $25^{\circ} \mathrm{C}$ or $31^{\circ} \mathrm{C}$, and used immediately to avoid diffusion of the test substance. Fifty to 100 larvae were lined along the separator, and allowed to move on the agar surface for $5 \mathrm{~min}$. Gustatory RI was calculated as RI = (the numbers of animals on the test half minus the number of animals on the control half)/(total number of the animals). Animals that left the gel surface were not counted.

Induction of dCREB2-b with heat shock. Heat shock treatment was performed as described previously (Honjo and Furukubo-Tokunaga, 2005). Food vials containing early third instar larvae were submerged in a $37.5^{\circ} \mathrm{C}$ water bath. The vials were then returned on the bench $\left(25^{\circ} \mathrm{C}\right)$ and kept for $30 \mathrm{~min}$ for larval recovery from the heat shock. Larvae were then collected and used for conditioning.

Statistics. Data are presented based on parametric tests (Student's $t$ test and ANOVA) in all figures for simplicity. However, considering the small number of samples, we also examined the data with nonparametric tests (either the Mann-Whitney $U$ test or the Kruskal-Wallis test) to further examine statistical significance. For multiple comparison among relevant groups, Dunnett's method and Dunn's method were used in conjunction with ANOVA and the Kruskal-Wallis test, respectively. In either test, $p<0.05$ was considered statistically significant.

Immunohistochemistry. Immunological staining of the larval and adult brains was performed as described previously (Kurusu et al., 2002). The antibodies used were as follows: Rat anti-CD8 $\alpha$ (Caltag) diluted 1:50; rabbit anti-TRIO diluted 1:1000 (Awasaki et al., 2000); rabbit antioctopamine (Advanced Targeting Systems); mouse anti-choline acetyl transferase (ChAt 4B1) (Takagawa and Salvattera, 1996) diluted 1:1000; mouse anti-FAS II (1D4) (Grenningloh et al., 1991) diluted 1:5; and Alexa-conjugated secondary antibodies (Invitrogen) diluted 1:1000. Confocal images were captured with a Zeiss LSM510 and processed using Adobe Photoshop.

Double-labeling study with fluorescent in situ hybridization and green fluorescent protein. Fluorescent in situ hybridization was performed as described previously (Kobayashi et al., 2006) with slight modifications. Digoxigenin-labeled RNA probes against tyramine $\beta$-hydroxylase were prepared with EST clones RH19793 and RH48375 obtained from the Drosophila Genomics Resource Center (Bloomington, IN). Hybridization was performed at $55^{\circ} \mathrm{C}$ overnight. Hybridization signals were detected with anti-DIG-POD (Roche Applied Science) and amplified by TSA Biotin System (PerkinElmer) using Streptavidin-Alexa 546 (Invitrogen). Green fluorescent protein (GFP) signals were enhanced with rabbit anti-GFP (Medical \& Biological Laboratories).

\section{Results}

\section{Aversive olfactory conditioning in Drosophila larvae}

To study aversive memory in larvae, we used our larval training protocol (Honjo and Furukubo-Tokunaga, 2005) with LIN as a CS odor and $0.1 \% \mathrm{QH}$ as an aversive US (LIN/QH). Associative training with LIN/QH, but not with either LIN alone or with $\mathrm{QH}$ alone, caused significant suppression in larval RI (Fig. $1 \mathrm{~A}$ ). This suppression was not specific to LIN as a significant RI decrement was also confirmed with another odorant, PA (Fig. $1 B$ ). Furthermore, suppression of larval RI required simultaneous exposure to the odor and $\mathrm{QH}$ as demonstrated in a temporal dissociation test (Fig. 1C), in which animals were successively exposed first to LIN and second to $\mathrm{QH}$, or vice versa. Exposure to LIN before $\mathrm{QH}$ (conditioning 5) led to slightly higher response possibly due to the latency between the odor exposure and the memory test, which causes a delayed nonassociative effect described previously (Honjo and Furukubo-Tokunaga, 2005). The difference was not significant $(p>0.1)$ although when compared with any of the other controls (conditions 2, 3, 4 and 6). However, only simultaneous exposure to LIN and $\mathrm{QH}$ (conditioning 1) reproduced 
significant suppression of larval olfactory response compared with any of the other conditionings $(p<0.05)$.

To examine nonspecific RI suppression by aversive US exposure, we tested larval olfactory response using a second odorant that was not used for training. When larvae were trained with $\mathrm{PA} / \mathrm{QH}$ or LIN/QH, only LIN/QH larvae showed significant RI suppression when tested with LIN (Fig. $1 D)$. Similarly, only larvae trained with $\mathrm{PA} / \mathrm{QH}$ showed RI suppression when tested with PA (Fig. 1E). Furthermore, in both tests, LIN/QH and PA/QH larvae exhibited significant difference in their response to the test odor $(p<0.01)$. Thus, these results argue that the observed decrement in larval response was not attributable to general olfactory suppression but rather represents discriminative and specific alteration in the response to the CS odor.

Using electric shock as a reinforcer, it has been shown that $d n c$ mutations abolish larval olfactory learning (Aceves-Piña and Quinn, 1979; Tully et al., 1994a). In addition, we have shown that larval appetitive learning depends on cAMP signaling (Honjo and Furukubo-Tokunaga, 2005). To determine whether cAMP signaling was similarly involved in the formation of aversive memory in our paradigm, we examined mutant larvae of $r u t^{1}$ and $d n c^{1}$, and found that both mutants failed to show significant RI decrement after aversive LIN/QH conditioning (Fig. $1 F$ ). To control integrity of sensory-motor responses, we measured larval olfactory response for LIN using the same agar plate assay used for learning tests (supplemental Table 1, available at www.jneurosci.org as supplemental material). The naive olfactory response of $\mathrm{rut}^{1}$ larvae and the quinine reactivity of $d n c^{1}$ larvae were slightly lower than those of wild-type (Canton-S) but the difference was not significant for both cases. Larval olfactory and gustatory responses were otherwise normal with these mutants. These results thus suggest that larval aversive memory induced by our paradigm depends on the cAMP signaling.

\section{Stability of the aversive memory induced with LIN/QH}

Previously, we showed that larval appetitive memory generated with LIN and SUC (LIN/SUC) lasted longer than $2 \mathrm{~h}$ (Honjo and Furukubo-Tokunaga, 2005). To determine the stability of the aversive memory induced by the LIN/QH training described above, we examined the temporal change of the larval olfactory response after training (Fig. 2). Despite the identical training procedure involving same odor (LIN) and same exposure time (30 min), larval
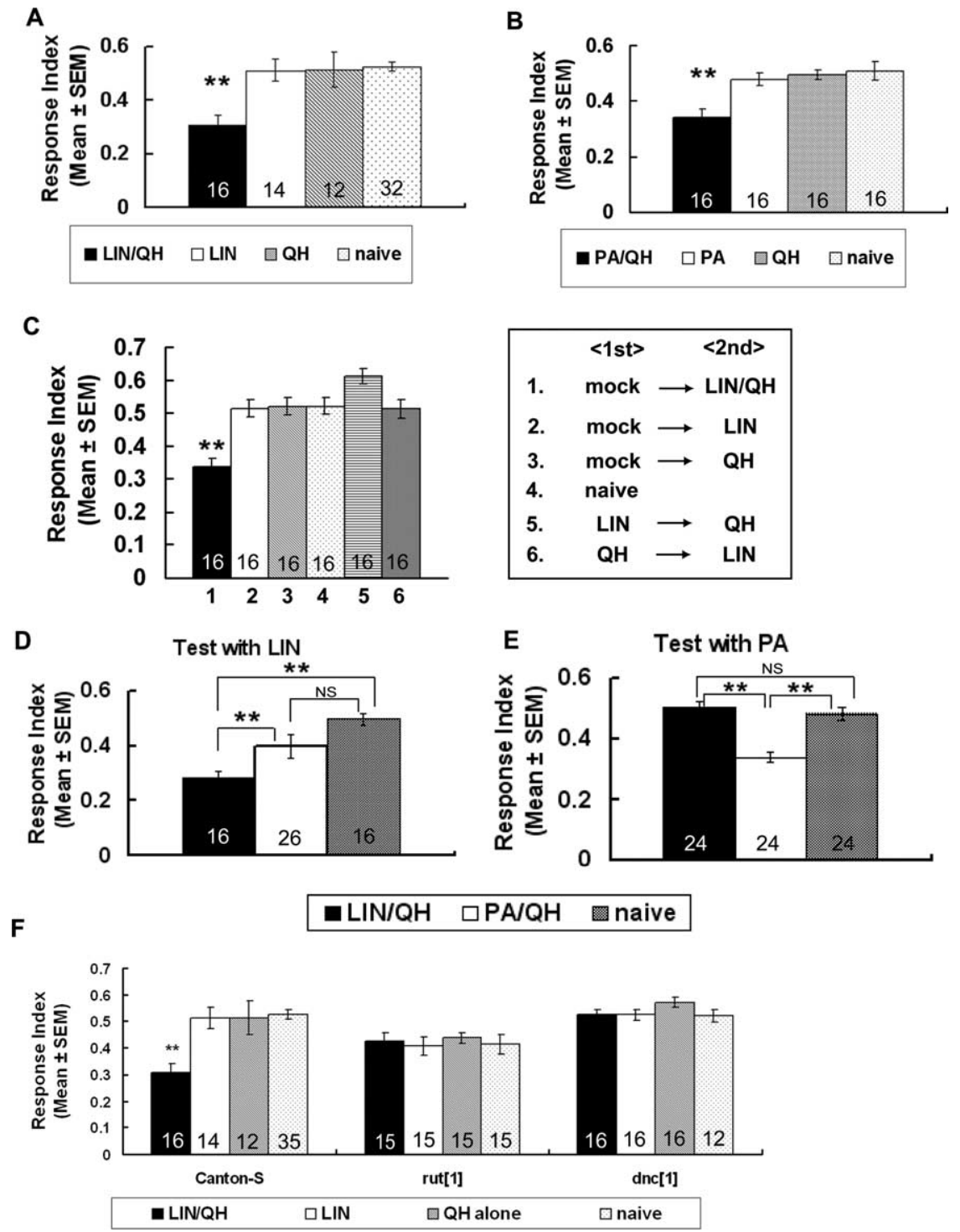

Figure 1. Characterization of aversive olfactory conditioning in Drosophila larvae. $\boldsymbol{A}, \boldsymbol{B}$, Larval aversive olfactory conditioning with LIN $(\boldsymbol{A})$ and PA $(\boldsymbol{B})$. Type of larval conditioning is indicated in the box: $\mathrm{LIN} / \mathrm{QH}$, exposure to LIN in association with $0.1 \% \mathrm{QH}$; $\mathrm{LIN}$, exposure to LIN in association with $\mathrm{DW} ; \mathrm{OH}, 0.1 \% \mathrm{QH}$ alone. The same odorant was used in the olfactory conditioning and test. Significant RI decrement was observed only when larvae were exposed to the odor in contingent with $\mathrm{QH}$ ( $\mathrm{LIN} / \mathrm{QH}$ in $\mathrm{A}$ and PA/QH in $\boldsymbol{B})\left({ }^{* *} p<0.01\right.$ by the Kruskal-Wallis test and Dunn's post hoc test, compared with any of the other three conditions; also confirmed by ANOVA). C, Temporal dissociation controls. Larvae were conditioned by LIN and QH either simultaneously or successively. Type of larval conditioning is indicated in the box. 1: mock and exposure to LIN in association with QH. 2: mock and exposure to LIN in association with DW. 3: mock and QH alone. 4: no conditioning (naive). 5: first exposed to LIN in association with DW, and then to $0.1 \% \mathrm{QH}$ without the odor. 6: first exposed to $0.1 \% \mathrm{QH}$ without the odor and then to LIN in association with DW. Each exposure time was $30 \mathrm{~min}$. Larvae were briefly rinsed after the first conditioning and transferred to another plate for the second conditioning. Note the procedure resulted in dissociation by a 1-2 min gap between the first and second treatments. Only temporally associative conditioning resulted in significant decrement of $\mathrm{RI}\left({ }^{* *} p<0.05\right.$ by the Kruskal-Wallis test followed by Dunn's post hoc test, compared with any of the other three conditions; also confirmed by ANOVA). D, E, Specificity of the larval olfactory response to the conditioned odor. D, Tests with LIN. Larvae were conditioned either with LIN or PA in association with $Q H$ and tested with LIN. $\boldsymbol{E}$, Tests with PA. Larvae were conditioned either with LIN or PA in association with QH and tested with PA. Note the larval RI was significantly decreased only to the odor that was paired with $\mathrm{QH}\left({ }^{* *} p<0.01\right.$, by the Kruskal-Wallis test followed by Dunn's post hoc test, compared with any of the other three conditions; also confirmed by ANOVA; NS, not significant). $\boldsymbol{F}$, Aversive memory in cAMP mutants. Type of larval conditioning is indicated in the box. The associative LIN/QH conditioning led to significant RI decrement for wild-type, but not for mutant, larvae. The number of each sample is indicated within the bar. ${ }^{* *} p<0.01$ by the Mann-Whitney U test, also confirmed by Student's $t$ test).

memory generated with the LIN/QH conditioning was lost in 20 $\min$ (Fig. 2A,F).

Because we used different US substances between LIN/SUC and LIN/QH trainings, we then compared larval gustatory re- 

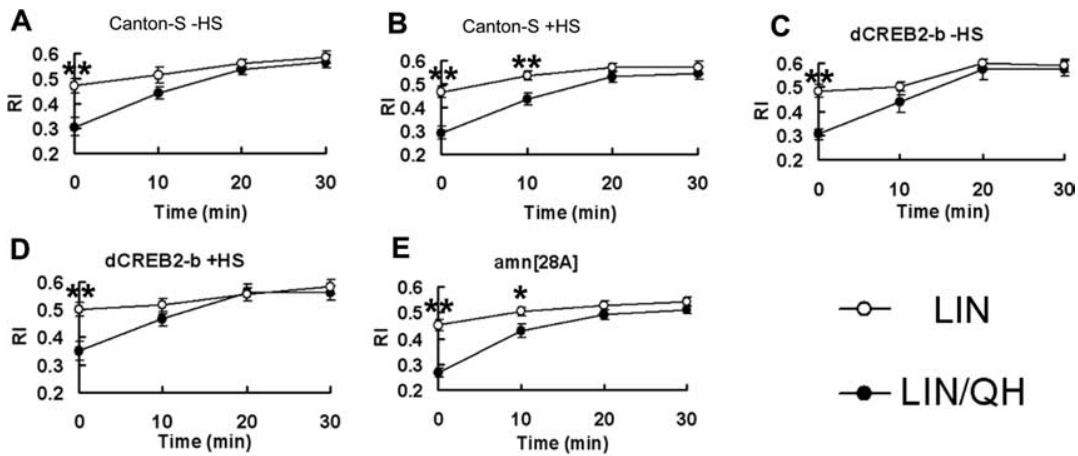

$\mathbf{F}$

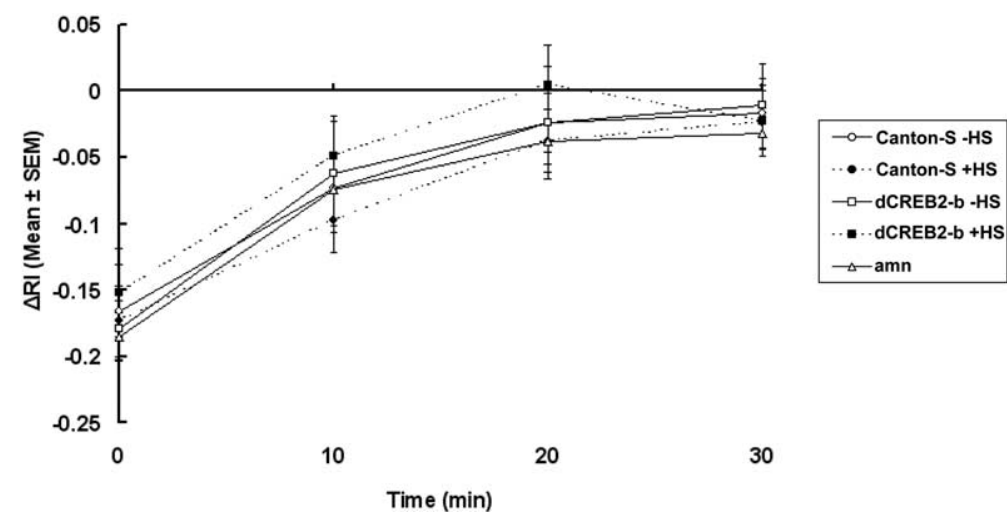

Figure 2. Larval aversive memory is short term. $\boldsymbol{A}-\boldsymbol{E}$, Temporal changes of larval olfactory response after $\mathrm{LIN} / \mathrm{QH}$ training. $\boldsymbol{A}$, Wild type without heat shock; $\boldsymbol{B}$, wild type with heat shock; $\boldsymbol{C}$, dCREB2-b without heat shock; $\boldsymbol{D}$, dCREB2-b with heat shock; and $\boldsymbol{E}$, $a m n^{28 A} .{ }^{*} p<0.05,{ }^{* *} p<0.01$ by the Mann-Whitney U test between LIN/QH and LIN, also confirmed by Student's test. In $B$ and $\boldsymbol{D}$, larvae were heat shocked at $37.5^{\circ} \mathrm{C}$ for $30 \mathrm{~min}$ before training. $\boldsymbol{F}$, Olfactory memory performances in wild-type and mutant larvae plotted in $\Delta$ RI. No significant difference was found among the memory scores of all experimental animals at all time points ( $p>0.65$ for all points by the Kruskal-Wallis test followed by Dunn's post hoc test; also confirmed by ANOVA). Each data point represents $\mathrm{Rl}$ of independent animal groups (average of 14-18 experiments).

sponses elicited by $1 \mathrm{~m}$ SUC and $0.1 \% \mathrm{QH}$ by agar plate assay. Although larvae showed opposite behaviors, response indices for the two US compounds were of similar magnitude at the concentrations used in training (supplemental Table 1, Canton-S, available at www.jneurosci.org as supplemental material), suggesting that the reinforcing power of the aversive $\mathrm{QH}$ stimuli was comparable with that of the appetitive SUC stimuli at least by the behavioral criteria. Moreover, initial memory scores are comparable between the LIN/SUC and LIN/QH conditionings (compare Fig. $2 F$ with Fig. $4 F$ of Honjo and Furukubo-Tokunaga, 2005), although the small suppression of initial memory in $a m n$ larvae observed after the appetitive LIN/SUC conditioning (Honjo and Furukubo-Tokunaga, 2005) was not detected after the aversive LIN/QH conditioning. These results suggest that the observed instability in the aversive memory induced with LIN/QH was unlikely to be caused by suboptimal memory induction. In addition, we found that aversive memory formed with $1 \mathrm{~m} \mathrm{NaCl}$ was also short lived (supplemental Fig. 1 , available at www.jneurosci.org as supplemental material).

Larval appetitive memory formed with LIN/SUC consists of short-term and medium-term components, the latter of which is lost by either amn mutation or suppression of CREB activity (Honjo and Furukubo-Tokunaga, 2005). amn mutant larvae exhibit lower initial memory and form only STM. Although initial memory performance is intact, appetitive memory in heatshocked dCREB2-b larvae is lost within $30 \mathrm{~min}$ (Honjo and Furukubo-Tokunaga, 2005). Whereas amn and CREB are in- volved in the formation of MTM and longterm memory (LTM), respectively, in the adult fly (Yin et al., 1994; DeZazzo et al., 1999; Waddell et al., 2000; Keene et al., 2004, 2006; Perazzona et al., 2004), memory components produced by each of these genes are yet to be dissociated in larvae.

In contrast to the appetitive memory induced with the LIN/SUC training, neither the initial memory nor its retention was affected in amn mutant larvae when larvae were aversively trained with LIN/QH (Fig. $2 B-F$ ). Likewise, no difference was detected for aversive memory in heat induced dCREB2-b larvae. Examination of larval sensory-motor activities indicated that amn larvae showed normal olfactory and gustatory responses in the agar plate tests (supplemental Table 1, available at www.jneurosci.org as supplemental material). Similarly, olfactory response of dCREB2-b larvae was not altered by heatshock treatment (supplemental Table 1, available at www.jneurosci.org as supplemental material). Gustatory response of dCREB2-b larvae was slightly higher with heat shock but the difference was not significant (supplemental Table 1, available at www.jneurosci.org as supplemental material). These results suggest that aversive memory formed with LIN/QH by this paradigm involves neither amn- nor CREB-dependent components, a feature consistent with its short-term stability described above.

\section{Synaptic output of larval MB neurons is required for retrieval} of aversive memory

In the adult fly, different subsets of $\mathrm{MB}$ neurons are used sequentially during odor memory processing, in which neurotransmission from the $\alpha^{\prime} / \beta^{\prime}$ neurons is required to acquire and stabilize both aversive and appetitive memory (Krashes et al., 2007; Krashes and Waddell, 2008), whereas neural transmission from $\alpha / \beta$ neurons is required for memory retrieval (Dubnau et al., 2001; McGuire et al., 2001; Schwaerzel et al., 2002, 2003; Krashes et al., 2007; Krashes and Waddell, 2008). In contrast to the multiple-lobe organization of the adult $\mathrm{MB}$, the larval $\mathrm{MB}$, whose neurons are classified into a single type that corresponds to the $\gamma$ group in the adult, exhibits a morphologically homogeneous projection pattern with only one dorsal lobe and one medial lobe, although concentric layer organization is found internally (Kurusu et al., 2002).

Despite the simple organization, synaptic output of larval MB neurons has been shown to be required for retrieval, but not for acquisition and retention, of larval appetitive memory formed with LIN/SUC (Honjo and Furukubo-Tokunaga, 2005). To determine the neural circuits for larval aversive memory induced with LIN/QH, we temporarily inactivated synaptic transmission of larval MB neurons by expressing UAS-shits1 (Kitamoto, 2001) under MB-GAL4 drivers, 201Y, and OK301, both of which drive specific MB expression in the larval brain (Kurusu et al., 2002; Honjo and FurukuboTokunaga, 2005). Most of the larval MB neurons are labeled with 


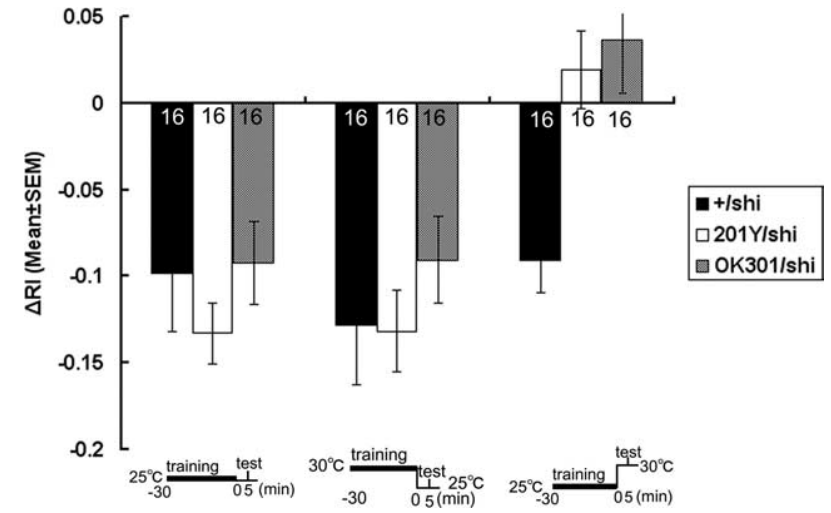

Figure 3. Synaptic output of $M B$ neurons is required for retrieval of larval aversive memory. Larval memory performance was tested at $5 \mathrm{~min}$ after aversive LIN/QH conditioning. UAS-shis ${ }^{\text {ts }}$ was expressed by either $201 Y$ or $0 K 301 \mathrm{GAL} 4$ drivers. The temperature shift protocol is indicated below each set of the graphs. No difference was detected in memory performance for 201Y/shit ${ }^{\text {ts } 1}$ and $0 K 301 /$ $s h i^{\text {ts1 }}$ larvae when both training and test were performed at $25^{\circ} \mathrm{C}$ or when training was performed at $30^{\circ} \mathrm{C}$ and test was performed at $25^{\circ} \mathrm{C}\left(p>0.5\right.$ for both types of larvae, compared with $+/ \mathrm{shi} i^{\text {ts } 1}$ by the Kruskal-Wallis test followed by Dunn's post hoc test, also confirmed by ANOVA). In contrast, olfactory memory was completely impaired in 201Y/shit ${ }^{\text {ts } 1}$ and $0 K 301 / \mathrm{shi}^{\text {ts1 }}$ larvae when trained at $25^{\circ} \mathrm{C}$ and tested at $30^{\circ} \mathrm{C}\left(p<0.05\right.$ for both types of larvae, compared with $+/ s h i^{\text {ts } 1}$ by the KruskalWallis test and Dunn's post hoc test, also confirmed by ANOVA).

201Y, whereas a more restricted subset of MB neurons is labeled by OK301 (Honjo and Furukubo-Tokunaga, 2005).

Larvae expressing UAS-sh $i^{\text {tsl }}$ by either MB driver showed normal 5 min memory when both training and test were performed at the permissive temperature $\left(25^{\circ} \mathrm{C}\right)$ (Fig. 3). Memory performance was also unaffected in $201 Y / s h i^{\text {tsl }}$ and $O K 301 /$ sh $^{\text {ts } 1}$ larvae when trained at the restrictive temperature $\left(30^{\circ} \mathrm{C}\right)$ and tested at the permissive temperature. In contrast, when trained at the permissive temperature and tested at the restrictive temperature, aversive memory performance was lost in both $201 Y / s h i^{\text {ts1 }}$ and $\mathrm{OK} 301 / \mathrm{shi}^{\mathrm{ts} 1}$, but not in the control $+/ \mathrm{shi}^{\mathrm{ts} 1}$, larvae.

Control experiments for sensory acuities showed that the naive olfactory response of $O K 301 / s h{ }^{\text {ts1 }}$ was higher at the restrictive temperature ( $p<0.05$ by the Mann-Whiney $U$ test) (supplemental Table 1, available at www.jneurosci.org as supplemental material). The quinine reactivity of $201 Y / s h i^{\text {ts } 1}$ larvae was slightly lower at $30^{\circ} \mathrm{C}$ but the difference was not significant $(p>$ $0.5)$. Otherwise, the olfactory and gustatory responses of $201 Y$ / $s h i^{\text {ts } 1}, O K 301 / s h i^{\text {ts } 1}$ and the control $+/ s h i^{\text {tsl }}$ larvae were not altered significantly between the permissive and the restrictive temperatures (supplemental Table 1, available at www.jneurosci.org as supplemental material).

These results demonstrate that, as with the larval appetitive memory induced with LIN/SUC, synaptic output of larval MB neurons is required for the retrieval, but not for the acquisition, of the larval aversive memory induced with LIN/QH. The result that the retrieval of appetitive and aversive memory is similarly blocked in $O K 301 /$ shi $^{\text {tsl }}$ larvae suggest that both types of memory traces might be localized to or mediated by an overlapping subset of $\mathrm{MB}$ neurons labeled by this driver of limited $\mathrm{MB}$ expression, although elucidation of the exact usage of different subsets of larval $\mathrm{MB}$ neurons awaits further behavioral and anatomical investigations.

\section{Synaptic output of DA and OA/TA neurons is differentially required for acquisition of larval aversive and appetitive memory}

Biogenic amines have critical functions in mediating the reinforcing effects of US in associative learning in insects (Hammer, 1993;
Hammer and Menzel, 1998; Schwaerzel et al., 2003; Unoki et al., 2005, 2006; Kim et al., 2007; Vergoz et al., 2007). In the adult fly, $\mathrm{OA}$ is necessary for the formation of sugar reward memory whereas synaptic output of DA neurons is required for acquisition, but not retrieval, of aversive memory induced with electric shock (Schwaerzel et al., 2003). Mutations of the dDA1 significantly suppress aversive olfactory learning, and moderately impair sugar-mediated learning (Kim et al., 2007). It is also shown that light-induced activation of larval DA and OA/tyraminergic (TA) neurons triggers aversive and appetitive learning, respectively, in Drosophila larvae (Schroll et al., 2006). However, whether the DA and OA/TA neurons are differentially required for larval aversive or appetitive olfactory learning remains to be demonstrated.

To identify the modulatory neurons involved in larval associative learning, we expressed $U A S-s h{ }^{\text {tsl }}$ in larval DA and OA/TA neurons using GAL4 drivers, TH-GAL4 (Friggi-Grelin et al., 2003) and TDC2-GAL4 (Cole et al., 2005), respectively. THGAL4 is expressed in larval DA neurons under the promoter of the tyrosine hydroxylase $(\mathrm{TH})$ gene, which is involved in DA synthesis. TH-GAL4 recapitulates most of the expression pattern of the tyrosine hydroxylase gene in the larval brain (supplemental Fig. $2 \mathrm{~A}$, available at www.jneurosci.org as supplemental material) (Friggi-Grelin et al., 2003). However, TDC2-GAL4 is expressed in larval OA/TA neurons under the promoter of the $t y$ rosine decarboxylase (TDC) gene. Double-labeling experiments confirmed that most of the TDC2-GAL4 neurons express tyramine $\beta$-hydroxylase mRNA (supplemental Fig. $2 B$, available at www.jneurosci.org as supplemental material), which converts TA to OA. Indeed, double labeling with an anti-OA antibody confirmed that TDC2-GAL4 soma, in particular, those in the subesophageal ganglia (SOG), and their extensions are immunoreactive for OA (supplemental Fig. 3, available at www. jneurosci.org as supplemental material).

When the $T H / s h i^{\text {ts1 }}$ or $T D C 2 /$ sh $^{t^{\text {ss } 1}}$ larvae were aversively trained with $\mathrm{QH}$ and tested at the permissive temperature $\left(25^{\circ} \mathrm{C}\right)$, both genotypes of larvae showed normal memory scores (Fig. $4 A$ ). However, when these larvae were trained at the restrictive temperature $\left(31^{\circ} \mathrm{C}\right)$ and tested at the permissive temperature, memory performance was abolished in $T H / s h i^{\text {tsl }}$, but not in TDC2/shits ${ }^{\text {ts }}$, larvae ( $p<0.01$ compared with $+/ s h i^{\text {ts } 1}$ larvae). However, $\mathrm{TH} / \mathrm{sh} i^{\text {tsl }}$ larvae exhibited significant memory performance when trained at the permissive temperature and tested at the restrictive temperature. Memory performance of TDC2/shits was also significant in the $25-31^{\circ} \mathrm{C}$ shift experiment (supplemental Table 2, available at www.jneurosci.org as supplemental material) $(p<0.01$ comparison between LIN/SUC and LIN alone conditionings by the Mann-Whitney $U$ test), and indistinguishable from that of the control $+/ s h i^{\text {ts } 1}$ larvae.

$+/ s h i^{\text {ts } 1}$ larvae showed lower performance in the $25-31^{\circ} \mathrm{C}$ shift compared with their performances in the other temperature shift experiments (not significant by the Kruskal-Wallis test, $p=0.05$ ) (also see supplemental Fig. $4 A$, available at www.jneurosci.org as

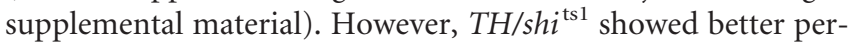
formance in the $25-31^{\circ} \mathrm{C}$ shift experiment compared with their performances in the $25-25^{\circ} \mathrm{C}$ shift experiment (not significant, $p>0.2$ by the Kruskal-Wallis test) (supplemental Fig. $4 A$, available at www.jneurosci.org as supplemental material), resulting a better performance when compared with the control $+/ s h{ }^{\text {tsl }}$ larvae $(p<0.05$ by the Kruskal-Wallis test followed by Dunn's post hoc test).

However, when $T H / s h i^{\text {ts1 }}$ or TDC2/shits ${ }^{\text {ts1 }}$ larvae were appetitively trained with SUC at restrictive temperature and tested at 


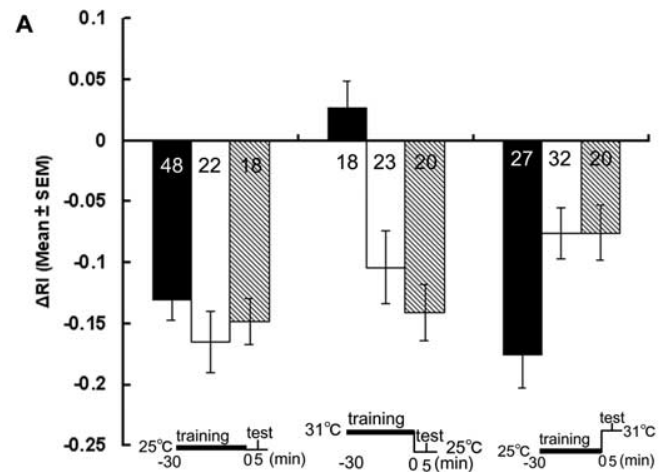

B

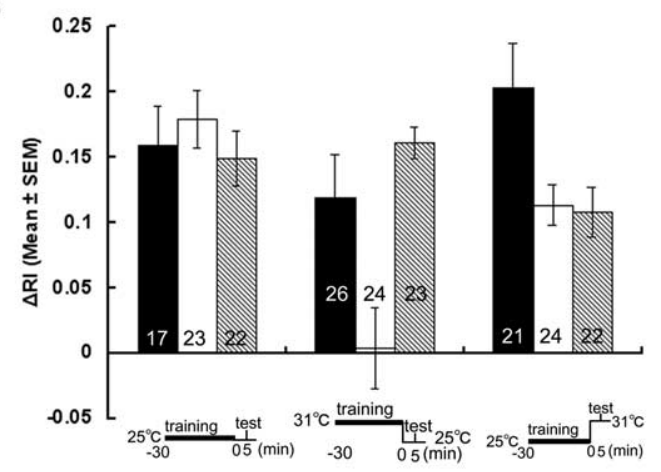

Figure 4. Synaptic output of monoaminergic neurons is differentially required for acquisition of appetitive and aversive memory. UAS-shits1 was driven by TH-GAL4 or TDC2-GAL4 to block synaptic transmission from DA or OA/TA neurons, respectively. The temperature shift protocol is indicated below each set of graphs. $A$, Aversive 5 min memory induced with LIN/QH. $T H / s h i^{t 51}$, but not $T D C 2 / s h i^{t 51}$, larvae exhibited significant memory impairment when trained at $31^{\circ} \mathrm{C}$ and tested at $25^{\circ} \mathrm{C}\left(p<0.01\right.$ compared with the $+/ s h i^{\text {ts } 1}$ by the Kruskal-Wallis test with Dunn's post hoc test, also confirmed by ANOVA). In the $25-31^{\circ}$ ( shift experiment, memory performance of $T H / s h i^{\text {ts } 1}$ larvae was higher than that of $+/$ shi $^{\text {ts1 }}$ larvae $(p<0.05$ by the Kruskal-Wallis test followed by Dunn's post hoc test) but not adversely altered. No difference was found between TDC2/shi ${ }^{\text {ts } 1}$ and $+/$ shi $^{\text {ts } 1}$ larvae in the $25-31^{\circ} \mathrm{C}$ shift experiment $(p>0.5$ by the Kruskal-Wallis test followed by Dunn's post hoc test, also confirmed by ANOVA), and both TDC2/shi ${ }^{\text {ts } 1}$ and $+/ s h i^{\text {ts1 }}$ larvae exhibited significant memory performance (see supplemental Table 2, available at www.jneurosci.org as supplemental material). However, neither $\mathrm{TH} / \mathrm{sh} i^{\text {ts1 }}$ nor TDC2/shi ${ }^{\text {ts1 }}$ showed memory defect in the $25-25^{\circ} \mathrm{C}$ shift experiment ( $p>0.5$ compared with $+/ s h i^{\text {ts } 1}$ by the Kruskal-Wallis test followed by Dunn's post hoc test also confirmed by ANOVA). B, Appetitive 5 min memory induced with LIN/SUC. TDC2/shi ${ }^{\text {ts }}$, but not $T H / s h i^{\text {ts }}$, larvae showed significant memory impairment when trained at $31^{\circ} \mathrm{C}$ and tested at $25^{\circ} \mathrm{C}\left(p<0.01\right.$ compared with the $+/ s h i^{\text {ts } 1}$ by the Kruskal-Wallis test followed by Dunn's post hoc test, also confirmed by ANOVA). In the $25-31^{\circ} \mathrm{C}$ shift experiment, memory performance of $T H / \mathrm{shi}^{\text {ts } 1}$ larvae was higher than that of $+/ \mathrm{shi}^{\mathrm{ts} 1}$ larvae $(p<0.05$ by the KruskalWallis test with Dunn's post hoc test) but not adversely altered. No difference was found between $T D C 2 / s h i^{\text {ts } 1}$ and $+/ \mathrm{shi}^{\mathrm{ts} 1}$ larvae in the $25-31^{\circ} \mathrm{C}$ shift experiment $(p>0.5$ by the Kruskal-Wallis test with Dunn's post hoc test, also confirmed by ANOVA), and both TDC2/shi ${ }^{\text {ts } 1}$ and $+/ s h i^{\text {ts } 1}$ types of larvae exhibited significant memory performance (see supplemental Table 2, available at www.jneurosci.org as supplemental material). However, neither $T H / s h i^{\text {ts } 1}$ nor TDC2/shi ${ }^{\text {ts } 1}$ showed memory defect in the $25-25^{\circ} \mathrm{C}$ shift experiment ( $p>0.5$ compared with $+/ s h i^{\text {ts1 }}$ by the Kruskal-Wallis test with Dunn's post hoc test also confirmed by ANOVA).

permissive temperature, memory performance was abolished in $T D C 2 / s h i^{\text {tsl }}$, but not in $T H / s h i^{\text {tsl }}$, larvae $(p<0.01$, compared with $+/ s h i^{\text {tsl }}$ larvae) (Fig. $4 B$ ). Normal memory performance was observed in both $T H / s h i^{\text {ts } 1}$ and $T D C 2 / s h i^{\text {ts } 1}$ larvae when trained at $25^{\circ} \mathrm{C}$ and tested also at $25^{\circ} \mathrm{C}(p>0.5$, compared with $+/ s h i^{\text {tsl }}$ larvae). $\mathrm{TH} / \mathrm{shi}^{\mathrm{ts}}$ larvae exhibited significant memory performance when trained at $25^{\circ} \mathrm{C}$ and tested at $31^{\circ} \mathrm{C}$ (supplemental Table 3, comparison between LIN/SUC and LIN alone conditionings by the Mann-Whitney $U$ test, available at www. jneurosci.org as supplemental material) $(p<0.01)$. Memory performance of $T D C 2 / s h i^{\text {ts } 1}$ was also significant in the $25-31^{\circ} \mathrm{C}$ shift experiment (supplemental Table 3, available at www. jneurosci.org as supplemental material) $(p<0.01$ comparison between LIN/SUC and LIN alone conditionings by the MannWhitney $U$ test), and indistinguishable from that of the control $+/$ shi $^{\text {tsl }}$ larvae.

As with the aversive memory performance, $+/ s h i^{\text {tsl }}$ larvae showed lower performance in the $25-31^{\circ} \mathrm{C}$ shift experiment with appetitive US (not significant, $p>0.1$, compared with their performances in the other temperature shift experiments by the Kruskal-Wallis test) (supplemental Fig. $4 B$, available at www. jneurosci.org as supplemental material). However, $\mathrm{TH} / \mathrm{shi}^{\mathrm{ts} 1} \mathrm{lar}$ vae again showed better performance in the $25-31^{\circ} \mathrm{C}$ shift experiment compared with their performances in the other temperature shift experiments (not significant, $p>0.5$ by the Kruskal-Wallis test) (supplemental Fig. $4 B$, available at www. jneurosci.org as supplemental material), resulting a higher performance when compared with the control $+/ s h i^{\text {tsl }}$ larvae $(p<$ 0.05 by the Kruskal-Wallis test followed by Dunn's post hoc test).

As described, $\mathrm{TH} / \mathrm{sh}^{\text {ts } 1}$ larvae exhibited better performance in the $25-31^{\circ} \mathrm{C}$ shift experiment when compared with the $+/ s h i^{\text {ts } 1}$ control in both aversive and appetitive memory tests. To examine whether the $\Delta \mathrm{RI}$ values of the $\mathrm{TH} / \mathrm{sh} i^{\text {tsl }}$ larvae in the $25^{\circ} \mathrm{C}-31^{\circ} \mathrm{C}$ shift experiment represent nonassociative components, we trained $\mathrm{TH} / \mathrm{sh} i^{\text {tsl }}$ larvae at $25^{\circ} \mathrm{C}$ by successively exposing them to the US and the CS odor in a temporally dissociated manner, and examined their memory performance at $31^{\circ} \mathrm{C}$. However, we failed to detect significant memory performance in this way with either aversive or appetitive US $(\Delta \mathrm{RI}=-0.05 \pm 0.03$ with $\mathrm{QH}$; $\Delta \mathrm{RI}=+0.01 \pm 0.03$ with SUC) (supplemental Tables 2 and 3, available at www.jneurosci.org as supplemental material) $(p>$ 0.5 , comparison between LIN/SUC and LIN alone by the MannWhitney $U$ test), suggesting that most, if not all, of the memory scores of the $\mathrm{TH} / \mathrm{sh} i^{\text {ts }}$ larvae in the $25-31^{\circ} \mathrm{C}$ shift experiment represent an associative component. We also examined whether the increased memory score of the $T H / s h i^{\text {ts } 1}$ larvae was caused by the genetic background of the TH-GAL4 chromosome, but found that the heterozygous $+/ T H$ control larvae exhibited memory scores that were comparable with that of $+/ s h i^{\text {tsl }}$ larvae $(\Delta \mathrm{RI}=$ $-0.10 \pm 0.03$ with QH; $\Delta \mathrm{RI}=+0.09 \pm 0.03$ with SUC) (supplemental Tables 2 and 3, available at www.jneurosci.org as supplemental material).

Although these data argue for that the higher memory score with $T H / s h i^{\text {tsl }}$ larvae is mostly caused by associative learning, it is an unexplained effect that is not understood. We therefore should be cautious in interpreting the $T H / s h i^{\text {tsl }}$ results in the $25-31^{\circ} \mathrm{C}$ shift experiment as an enhanced memory performance. As described above, the $\Delta \mathrm{RI}$ value of $\mathrm{TH} / \mathrm{shi}^{\mathrm{ts} 1}$ larvae in the 25$31^{\circ} \mathrm{C}$ shift experiment was not increased significantly from their $\Delta \mathrm{RI}$ value in the $25-25^{\circ} \mathrm{C}$ control for either aversive or appetitive memory (supplemental Fig. 4, available at www.jneurosci.org as supplemental material). Furthermore, although the olfactory response of $T H / s i^{\text {tsl }}$ larvae was significantly altered after both types of the associative training, $\mathrm{TH} / \mathrm{sh}^{\text {tsl }}$ larvae exhibited lower olfactory response for LIN in the $25-31^{\circ} \mathrm{C}$ shift experiment (supplemental Tables 2 and 3, available at www.jneurosci.org as supplemental material), thus suggesting irregularity in their sensorymotor activities specifically induced in the temperature shift experiment. Indeed, $\mathrm{TH} / \mathrm{sh} i^{\text {ts } 1}$ larvae exhibited complex response to LIN in the memory test under the $25-31^{\circ} \mathrm{C}$ temperature shift; they were initially repelled shortly but then attracted by the test 
odor, whereas they showed straightforward response to the odor at the other temperature conditions as with the other larvae including $+/$ sh $^{\mathrm{ts} 1}$.

In other respects, olfactory responses of the $T H / s h i^{\text {ts1 }}, T D C 2 /$ $s h i^{\text {ts } 1}$ and $+/ s h i^{\text {tsl }}$ larvae did not differ between the permissive and restrictive temperatures (supplemental Table 1, available at www.jneurosci.org as supplemental material). Both $\mathrm{TH} / \mathrm{shi}^{\mathrm{ts} 1}$ and TDC2/shits larvae showed higher sugar response at the restrictive temperature, but gustatory reactivity of $\mathrm{TH} / \mathrm{shi}^{\mathrm{ts} 1}$, $T D C 2 / s h i^{\text {ts1 }}$ and $+/ s h i^{\text {tsl }}$ larvae was not altered adversely at the restrictive temperature (supplemental Table 1, available at www.jneurosci.org as supplemental material). These results thus indicate that the memory deficits of $T H / s h i^{\text {ts1 }}$ and $T D C 2 / s h i^{\text {ts } 1}$ larvae observed in the acquisition blockade $\left(31-25^{\circ} \mathrm{C}\right.$ shift experiment) are unlikely to be caused by sensory-motor defects.

As a whole, these results confirm that the monoamines DA and OA/TA indeed play important roles in mediating the US signals in larval associative learning, and demonstrate that neural transmission of DA and OA/TA neurons is differentially required for acquisition of aversive and appetitive larval memory, respectively. It should be noted, however, that our results do not exclude the involvement of other transmitters that might be coreleased by the DA or OA/TA neurons targeted by the GAL4 drivers.

\section{DA and OA/TA neurons exhibit spatially distinct innervation patterns on larval $\mathrm{MB}$ and $\mathrm{AL}$}

The fact that synaptic transmission of $\mathrm{MB}$ neurons is required to retrieve both aversive and appetitive memory suggests that both types of memory might be localized to larval $\mathrm{MB}$ neurons or upstream circuits such as AL neurons. Although our results indicated that synaptic output of DA and OA/TA neurons were differentially required for the acquisition of aversive and appetitive larval memory, respectively, the underlying mechanisms by which these monoaminergic neurons convey the US information into the memory circuitry remained to be elucidated. As a way to answer this question, we investigated the local projection patterns of the DA and OA/TA neurons in MB and AL.

In the adult brain, DA neurons innervated the $\alpha / \alpha^{\prime}$-lobes, the heel, parts of the $\beta / \gamma$-lobes, and less densely the calyx (supplemental Fig. 5A, $B$, available at www.jneurosci.org as supplemental material) (see also Riemensperger et al., 2005; Zhang et al., 2007). In addition, DA neurons exhibited interglomerulus innervation in ALs (supplemental Fig. 5C, available at www.jneurosci.org as supplemental material). Similarly, OA/TA neurons projected multiple parts of the adult MBs innervating the heel, parts of the $\gamma$-lobe, and the calyx (supplemental Fig. 6A, $B$, available at www. jneurosci.org as supplemental material) (Sinakevitch and Strausfeld, 2006). Dense innervation in the glomeruli of the AL was also evident (supplemental Fig. 6C, available at www.jneurosci.org as supplemental material).

In contrast to the complex and partially overlapping innervation patterns of the DA and OA/TA neurons in the adult brain, projection patterns of these monoaminergic neurons were much simpler in the larval brain, and exhibited distinctive and rather complementary innervation patterns in $\mathrm{MB}$ and AL. Thus, whereas DA neurons densely ramified on the heel and the vertical lobe of the larval MB (Fig. 5A), no innervation was detected in the larval calyx and AL (Fig. $5 B, C$ ). In contrast, OA/TA neurons exhibited little innervation on the vertical lobe (Fig. 5D). Finally, $\mathrm{OA} / \mathrm{TA}$ neurons intensively innervated both the calyx and AL (Fig. $5 E, F$ ), in which a large number of OA puncta were observed along the projections of OA/TA neurons (supplemental Fig. 7, available at www.jneurosci.org as supplemental material). Most part of the medial lobe remained uninnervated by either DA or OA/TA neurons (data not shown).

\section{Discussion}

\section{Aversive conditioning in Drosophila larvae}

Because of its simple neural organization, larval learning in Drosophila has become an increasingly important model system (for review, see Gerber and Stocker, 2007). In the present study, we have characterized larval aversive memory induced by a paradigm we described previously with appetitive US (Honjo and Furukubo-Tokunaga, 2005). Control studies demonstrated that the induced difference in the larval olfactory response $(\Delta \mathrm{RI})$ is specific to the CS odor, and requires temporal association of aversive US and olfactory CS. Moreover, we have shown that larval aversive memory induced with LIN/QH or LIN/NaCl is short lived despite that the same training protocol induces more stable memory with LIN/SUC (Honjo and Furukubo-Tokunaga, 2005).

Gerber and Hendel (2006) described that larval aversive memory with gustatory US requires the presence of the aversive cue for its recall. However, we detected memory performance without aversive cue in the test plate (Fig. 1) and found no difference in memory performance by the inclusion of $\mathrm{QH}$ in the test plate (data not shown). The exact reason for this discrepancy is yet to be analyzed, but several differences are noteworthy. Whereas Gerber and Hendel (2006) train larvae reciprocally with CS (+) and CS (-) odors and examine differential odor preference, our protocol includes only a single CS odor and dose not involve odor discrimination task during memory retrieval. It is also noteworthy that the majority of larvae $(88 \%)$ ingest $\mathrm{QH}$ in our protocol, whereas larvae rarely take up QH-containing gel in Hendel et al. (2005). Given that larvae have both external and internal gustatory neurons (Python and Stocker, 2002; Colomb et al., 2007), ingestion of US substance may induce additional stimulation of internal gustatory receptors. Alternatively, ingestion itself and/or maintenance of bitter substance in the gut could contribute to memory formation and retrieval in our protocol.

\section{Differential stability of appetitive and aversive memory}

In contrast to the medium-term stability of appetitive memory induced with LIN/SUC, larval aversive memory induced with $\mathrm{LIN} / \mathrm{QH}$ or $\mathrm{LIN} / \mathrm{NaCl}$ is short lived, although we use the same CS odor, the same US modality, and the identical training paradigm. However, our results do not exclude the possibility of inducing longer-lived memory with aversive training. Whereas AcevesPiña and Quinn (1979) described that larval aversive memory induced with electric shock is lost in $30 \mathrm{~min}$ and independent of amn, Tully et al. (1994a) described that larval aversive memory induced with repetitive electric shocks requires amn and lasts through metamorphosis, suggesting that longer-lived memory including a CREB-dependent consolidated memory would be induced in larvae with aversive US depending on the training protocol. Moreover, it is also established that repetitive training with electric shock induces LTM in the adult fly (Tully et al., 1994b).

However, studies with appetitive US suggest that longer-lived memory can be induced with appetitive US in adult flies after much fewer trials (Tempel et al., 1983; Krashes and Waddell, 2008). Indeed, recent work (Krashes and Waddell, 2008) demonstrates that appetitive olfactory conditioning produces radish and protein synthesis-dependent long-term memory in the adult fly only by a single $2 \mathrm{~min}$ training session. While differences in the 
Merge
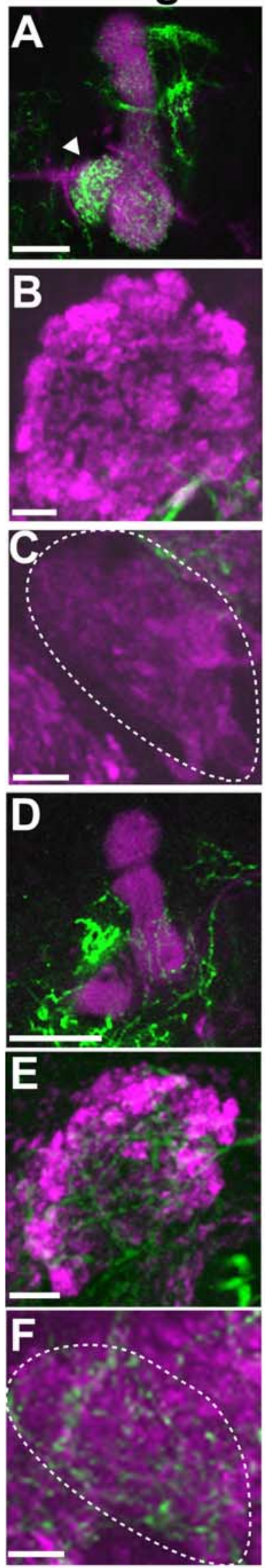

FasII / ChAt
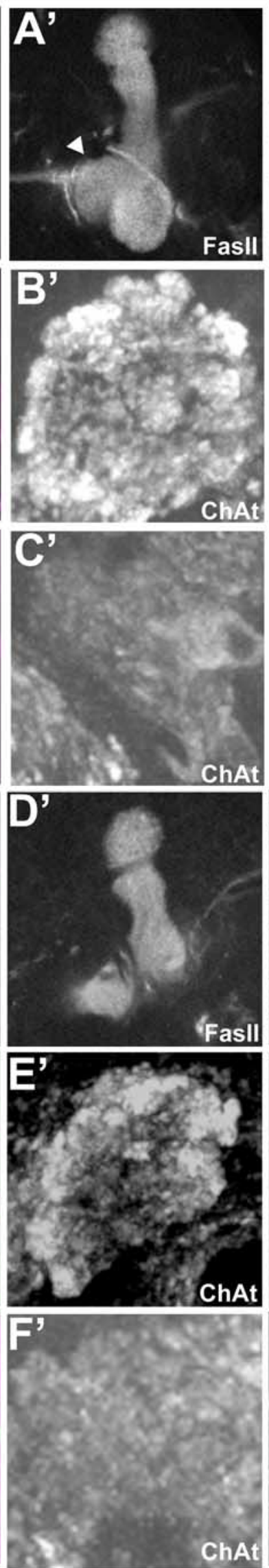
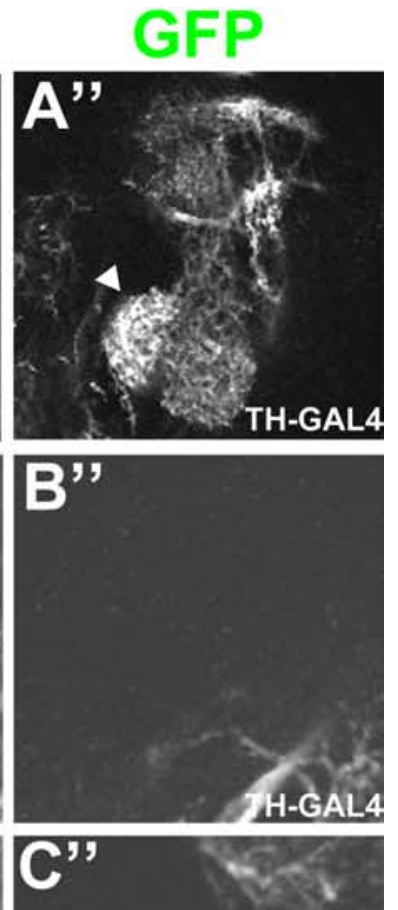

TH-GAL4
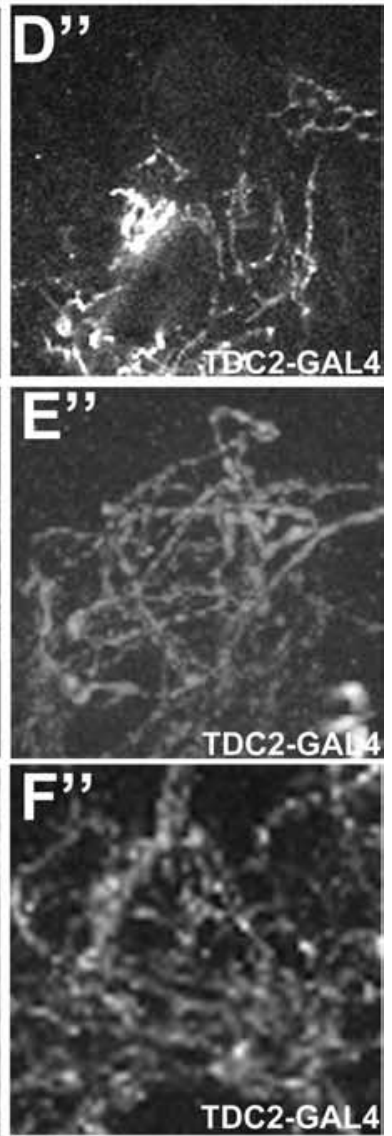

sensory modality of the US, the number of training cycles, and the physiological state of the animals (starved for reward conditioning) undermine direct comparison, combined with our results, these results suggest differential memory induction mechanisms in the brain that might be predisposed for more efficient induction of longer-lived memory with appetitive reinforcement.

\section{Differential functions of}

monoaminergic neurons in memory induction

Mutational and pharmacological studies on insect associative learning emphasize the importance of monoaminergic systems in different types of reinforcements (Hammer and Menzel, 1998; Schwaerzel et al., 2003; Unoki et al., 2005, 2006; Kim et al., 2007; Vergoz et al., 2007). In the adult fly, OA is necessary for the formation of sugar reward memory, whereas synaptic output of DA neurons is required for acquisition, but not retrieval, of electric shock memory (Schwaerzel et al., 2003). In honeybees, the octopaminergic VUMmx1 neuron, which projects bilaterally to $\mathrm{AL}$, $\mathrm{MB}$, and lateral protocerebrum, mediates the reinforcing function of sugar US in reward conditioning of proboscis extension response (Hammer, 1993). Aversive learning in honeybees depends on DA, but not OA, receptors (Vergoz et al., 2007). Differential reinforcing properties of OA/TA and DA neurons was also examined in Drosophila larvae by expressing Channelrhodopsin-2 in the larval monoaminergic neurons (Schroll et al., 2006). Thus, they have shown that light-induced activation of larval OA/TA or DA neurons is sufficient to induce appetitive and aversive learning, respectively. The result of the present study that the synaptic activity of $\mathrm{OA} / \mathrm{TA}$ or DA neurons is indeed differentially required for appetitive or aversive

Figure 5. Distinct projection patterns of the DA and OA/TA neurons in the larval brain. $A-C$, Innervation patterns of $D A$ neurons on MB and AL. In $\boldsymbol{C}$ and $\boldsymbol{F}$, the larval AL neuropil is demarcated with dotted circle. Note DA neurons densely innervate the MB heel (arrowhead) and the vertical lobe ( $A-$ $\left.A^{\prime \prime}\right)$, but not the calyx $\left(B-B^{\prime \prime}\right)$ and the AL glomeruli $\left(\boldsymbol{C}-C^{\prime \prime}\right)$. $D-F$, Innervation patterns of $O A / T A$ neurons on $M B$ and $A L$. $O A / T A$ neurons intensively innervate the $M B$ calyx $\left(\boldsymbol{E}-\boldsymbol{E}^{\prime \prime}\right)$ and AL glomeruli $\left(\boldsymbol{F}-\boldsymbol{F}^{\prime \prime}\right)$, but not the MB lobes $\left(\boldsymbol{D}-\boldsymbol{D}^{\prime \prime}\right)$. The diffuse OA/TA neuron projections around the lobes $\left(\boldsymbol{D}-\boldsymbol{D}^{\prime}\right)$ have no direct contact on the lobes. Brains were immunolabeled for the indicated marker. Innervation patterns of DA and OA/TA neurons were visualized with UAS-mCD8::GFP using TH-GAL4 $(\boldsymbol{A}-\boldsymbol{C})$ or TDC2-GAL4 $(\boldsymbol{D}-\boldsymbol{F})$. Early third instar brain. Scale bars: $(\boldsymbol{A}, \boldsymbol{D}) 20 \mu \mathrm{m} ;(\boldsymbol{B}, \boldsymbol{C}, \boldsymbol{E}, \boldsymbol{F}) 5 \mu \mathrm{m}$. 
larval learning further supports the notion that different reinforcing mechanisms involving monoamine modulators are responsible for the induction of the two types of memory in the insect brain.

However, Kim et al. (2007) showed that, in addition to severe impairment of electric shock-mediated aversive learning, $\mathrm{D}_{1}-\mathrm{DA}$ receptor mutations exhibit moderate impairment of sugar-mediated learning, suggesting that DA signaling also is required for appetitive learning in the adult fly. The discrepancy between this mutant study and the study with $\mathrm{TH}$ GAL4/shi ${ }^{\text {ts1 }}$ flies (Schwaerzel et al., 2003) might in part be explained by extensive physiological and/or developmental alterations caused by chronic loss of DA signaling by the genetic disruptions in the mutants, which could alter other brain functions affecting associative learning, such as arousal and/or attention states (Wu et al., 2000; Andretic et al., 2005; van Swinderen, 2007; Seugnet et al., 2008). Whether $\mathrm{dDA} 1$ is required for both appetitive and aversive memory is yet to be demonstrated in larvae.

\section{Differential US-CS convergence circuitries in appetitive and aversive memories}

In associative learning, the strength of the association between CS and US is thought to determine learning efficacy, and memory is formed at the convergence site of the two stimuli in the brain by altering interacting synaptic strength. Given that both aversive and appetitive memory traces are stored in partially overlapping neural circuitries that are upstream of the MB output synapses, how do different types of reinforcement then lead to different efficacy in inducing longer-lived memory components even with a same CS odorant? It has been shown that olfactory learning is completely abolished by MB expression of a constitutive active $\mathrm{G} \alpha$ protein (Connolly et al., 1996). Kenyon cells express G-protein-coupled receptors for the monoamines that represent the US reinforcing property; both OA and DA receptors are preferentially expressed in MB neurons (Han et al., 1996, 1998). Whereas little is known about the intracellular biochemical events triggered by the activation of these receptors, different G-protein-coupled receptors for the monoamines might trigger distinctive molecular components, such as A-kinase anchoring proteins (Lu et al., 2007; Schwaerzel et al., 2007), that may differentiate the efficacy in inducing longer-lived memory within an overlapping set of neurons.

However, differential efficacy in longer-lived memory induction might, in part, be accounted for by the neural circuits that mediate reinforcing US signals (Fig. 6). The sugar reward information sensed by gustatory sensory neurons is first transmitted to SOG, and further conveyed to the higher memory centers in the larval brain (Colomb et al., 2007; Vosshall and Stocker, 2007). Intriguingly, the larval OA/TA neurons exhibit intensive innervation on the dendritic structures of $\mathrm{AL}$ and $\mathrm{MB}$, suggesting that the sugar-US and the odor-CS signals converge on both sites to form memory traces (Fig. 6A). This duplicate convergence pattern of the reward-US and the odor-CS circuitries could, in part, account for the disposition for more efficient generation of stable memory components with appetitive US. With regards to this point, it is noteworthy that Thum et al. (2007) suggested that appetitive memory traces might be localized to both the Kenyon cells and the AL projection neurons in the adult fly. It is also noteworthy that local OA injection to either AL or MB, but not the lateral protocerebrum, produces associative reward learning in honeybees (Hammer and Menzel, 1998).

In contrast, the aversive $\mathrm{QH}$ information sensed by bitter sensing neurons is transmitted by DA neurons to only the MB lobe in the larval brain (Fig. $5 A-C$ ). Consequently, the odor CS and the aversive US are likely to converge on MB alone. Moreover, the US and CS signals were conveyed to the spatially distant subregions of the Kenyon cells (Fig. 6B). Considering these differential US-CS convergence patterns, we suggest that, although animals can learn to associate a given odors with various environmental cues by training, the efficacy of inducing longer-lived memory components might be predisposed by the innervation patterns of the endogenous reinforcing circuits in the brain that are genetically programmed through neural development.

Behavioral genetic studies with Drosophila have revealed a large number of genes and molecules involved in learning and memory, but the pivotal information as to the neurons and neural networks that mediate memory is still limited. The simple 
organization of the larval brain will help to identify the functional neural circuits in memory at a promising resolution.

\section{References}

Aceves-Piña EO, Quinn WG (1979) Learning in normal and mutant Drosophila larvae. Science 206:93-96.

Andretic R, van Swinderen B, Greenspan RJ (2005) Dopaminergic modulation of arousal in Drosophila. Curr Biol 15:1165-1175.

Awasaki T, Saito M, Sone M, Suzuki E, Sakai R, Ito K, Hama C (2000) The Drosophila trio plays an essential role in patterning of axons by regulating their directional extension. Neuron 26:119-131.

Cole SH, Carney GE, McClung CA, Willard SS, Taylor BJ, Hirsh J (2005) Two functional but noncomplementing Drosophila tyrosine decarboxylase genes: distinct roles for neural tyramine and octopamine in female fertility. J Biol Chem 280:14948-14955.

Colomb J, Grillenzoni N, Ramaekers A, Stocker RF (2007) Architecture of the primary taste center of Drosophila melanogaster larvae. J Comp Neurol 502:834-847.

Connolly JB, Roberts IJ, Armstrong JD, Kaiser K, Forte M, Tully T, O’Kane CJ (1996) Associative learning disrupted by impaired Gs signaling in Drosophila mushroom bodies. Science 274:2104-2107.

Davis RL (2005) Olfactory memory formation in Drosophila: from molecular to systems neuroscience. Annu Rev Neurosci 28:275-302.

DeZazzo J, Xia S, Christensen J, Velinzon K, Tully T (1999) Developmental expression of an $\operatorname{amn}(+)$ transgene rescues the mutant memory defect of amnesiac adults. J Neurosci 19:8740-8746.

Dubnau J, Grady L, Kitamoto T, Tully T (2001) Disruption of neurotransmission in Drosophila mushroom body blocks retrieval but not acquisition of memory. Nature 411:476-480.

Dudai Y, Jan YN, Byers D, Quinn WG, Benzer S (1976) dunce, a mutant of Drosophila deficient in learning. Proc Natl Acad Sci U S A 73:1684-1688.

Friggi-Grelin F, Coulom H, Meller M, Gomez D, Hirsh J, Birman S (2003) Targeted gene expression in Drosophila dopaminergic cells using regulatory sequences from tyrosine hydroxylase. J Neurobiol 54:618-627.

Gerber B, Hendel T (2006) Outcome expectations drive learned behaviour in larval Drosophila. Proc Biol Sci 273:2965-2968.

Gerber B, Stocker RF (2007) The Drosophila larva as a model for studying chemosensation and chemosensory learning: a review. Chem Senses 32:65-89.

Grenningloh G, Rehm EJ, Goodman CS (1991) Genetic analysis of growth cone guidance in Drosophila: fasciclin II functions as a neuronal recognition molecule. Cell 67:45-57.

Hammer M (1993) An unidentified neuron mediates the unconditioned stimulus in associative olfactory learning in honeybees. Nature 366:59-63.

Hammer M, Menzel R (1998) Multiple sites of associative odor learning as revealed by local brain microinjections of octopamine in honeybees. Learn Mem 5:146-156.

Han KA, Millar NS, Grotewiel MS, Davis RL (1996) DAMB, a novel dopamine receptor expressed specifically in Drosophila mushroom bodies. Neuron 16:1127-1135.

Han KA, Millar NS, Davis RL (1998) A novel octopamine receptor with preferential expression in Drosophila mushroom bodies. J Neurosci 18:3650-3658.

Heimbeck G, Bugnon V, Gendre N, Häberlin C, Stocker RF (1999) Smell and taste perception in Drosophila melanogaster larva: toxin expression studies in chemosensory neurons. J Neurosci 19:6599-6609.

Heisenberg M (2003) Mushroom body memoir: from maps to models. Nat Rev Neurosci 4:266-275.

Hendel T, Michels B, Neuser K, Schipanski A, Kaun K, Sokolowski MB, Marohn F, Michel R, Heisenberg M, Gerber B (2005) The carrot, not the stick: appetitive rather than aversive gustatory stimuli support associative olfactory learning in individually assayed Drosophila larvae. J Comp Physiol A Neuroethol Sens Neural Behav Physiol 191:265-279.

Honjo K, Furukubo-Tokunaga K (2005) Induction of cAMP response element-binding protein-dependent medium-term memory by appetitive gustatory reinforcement in Drosophila larvae. J Neurosci 25:7905-7913.

Keene AC, Waddell S (2007) Drosophila olfactory memory: single genes to complex neural circuits. Nat Rev Neurosci 8:341-354.

Keene AC, Stratmann M, Keller A, Perrat PN, Vosshall LB, Waddell S (2004) Diverse odor-conditioned memories require uniquely timed dorsal paired medial neuron output. Neuron 44:521-533.

Keene AC, Krashes MJ, Leung B, Bernard JA, Waddell S (2006) Drosophila dorsal paired medial neurons provide a general mechanism for memory consolidation. Curr Biol 16:1524-1530.

Kim YC, Lee HG, Han KA (2007) D1 dopamine receptor dDA1 is required in the mushroom body neurons for aversive and appetitive learning in Drosophila. J Neurosci 27:7640-7647.

Kitamoto T (2001) Conditional modification of behavior in Drosophila by targeted expression of a temperature-sensitive shibire allele in defined neurons. J Neurobiol 47:81-92.

Kobayashi M, Michaut L, Ino A, Honjo K, Nakajima T, Maruyama Y, Mochizuki H, Ando M, Ghangrekar I, Takahashi K, Saigo K, Ueda R, Gehring WJ, Furukubo-Tokunaga K (2006) Differential microarray analysis of Drosophila mushroom body transcripts using chemical ablation. Proc Natl Acad Sci U S A 103:14417-14422.

Krashes MJ, Waddell S (2008) Rapid consolidation to a radish and protein synthesis-dependent long-term memory after single-session appetitive olfactory conditioning in Drosophila. J Neurosci 28:3103-3113.

Krashes MJ, Keene AC, Leung B, Armstrong JD, Waddell S (2007) Sequential use of mushroom body neuron subsets during Drosophila odor memory processing. Neuron 53:103-115.

Kurusu M, Awasaki T, Masuda-Nakagawa LM, Kawauchi H, Ito K, Furukubo-Tokunaga K (2002) Embryonic and larval development of the Drosophila mushroom bodies: concentric layer subdivisions and the role of fasciclin II. Development 129:409-419.

Lee T, Luo L (1999) Mosaic analysis with a repressible cell marker for studies of gene function in neuronal morphogenesis. Neuron 22:451-461.

Livingstone MS, Sziber PP, Quinn WG (1984) Loss of calcium/calmodulin responsiveness in adenylate cyclase of rutabaga, a Drosophila learning mutant. Cell 137:205-215.

Lu Y, Lu YS, Shuai Y, Feng C, Tully T, Xie Z, Zhong Y, Zhou HM (2007) The AKAP Yu is required for olfactory long-term memory formation in Drosophila. Proc Natl Acad Sci U S A 104:13792-13797.

Margulies C, Tully T, Dubnau J (2005) Deconstructing memory in Drosophila. Curr Biol 15:R700-R713

McGuire SE, Le PT, Davis RL (2001) The role of Drosophila mushroom body signaling in olfactory memory. Science 293:1330-1333.

Perazzona B, Isabel G, Preat T, Davis RL (2004) The role of cAMP response element-binding protein in Drosophila long-term memory. J Neurosci 24:8823-8828.

Python F, Stocker RF (2002) Adult-like complexity of the larval antennal lobe of $D$. melanogaster despite markedly low numbers of odorant receptor neurons. J Comp Neurol 445:374-387.

Ramaekers A, Magnenat E, Marin EC, Gendre N, Jefferis GS, Luo L, Stocker RF (2005) Glomerular maps without cellular redundancy at successive levels of the Drosophila larval olfactory circuit. Curr Biol 15:982-992.

Riemensperger T, Völler T, Stock P, Buchner E, Fiala A (2005) Punishment prediction by dopaminergic neurons in Drosophila. Curr Biol 15:1953-1960.

Schroll C, Riemensperger T, Bucher D, Ehmer J, Völler T, Erbguth K, Gerber B, Hendel T, Nagel G, Buchner E, Fiala A (2006) Light-induced activation of distinct modulatory neurons triggers appetitive or aversive learning in Drosophila larvae. Curr Biol 16:1741-1747.

Schwaerzel M, Heisenberg M, Zars T (2002) Extinction antagonizes olfactory memory at the subcellular level. Neuron 35:951-960.

Schwaerzel M, Monastirioti M, Scholz H, Friggi-Grelin F, Birman S, Heisenberg M (2003) Dopamine and octopamine differentiate between aversive and appetitive olfactory memories in Drosophila. J Neurosci 23:10495-10502.

Schwaerzel M, Jaeckel A, Mueller U (2007) Signaling at A-kinase anchoring proteins organizes anesthesia-sensitive memory in Drosophila. J Neurosci 27:1229-1233.

Seugnet L, Suzuki Y, Vine L, Gottschalk L, Shaw PJ (2008) D1 receptor activation in the mushroom bodies rescues sleep-loss-induced learning impairments in Drosophila. Curr Biol 18:1110-1117.

Sinakevitch I, Strausfeld NJ (2006) Comparison of octopamine-like immunoreactivity in the brains of the fruit fly and blow fly. J Comp Neurol 494:460-475

Takagawa K, Salvattera P (1996) Analysis of choline acetyltransferase protein in temperature sensitive mutant flies using newly generated monoclonal antibody. Neurosci Res 24:237-243.

Tempel BL, Bonini N, Dawson DR, Quinn WG (1983) Reward learning in normal and mutant Drosophila. Proc Natl Acad Sci U S A 80:1482-1486.

Thum AS, Jenett A, Ito K, Heisenberg M, Tanimoto H (2007) Multiple 
memory traces for olfactory reward learning in Drosophila. J Neurosci 27:11132-11138.

Tully T, Cambiazo V, Kruse L (1994a) Memory through metamorphosis in normal and mutant Drosophila. J Neurosci 14:68-74.

Tully T, Preat T, Boynton SC, Del Vecchio M (1994b) Genetic dissection of consolidated memory in Drosophila. Cell 79:35-47.

Unoki S, Matsumoto Y, Mizunami M (2005) Participation of octopaminergic reward system and dopaminergic punishment system in insect olfactory learning revealed by pharmacological study. Eur J Neurosci 22:1409-1416.

Unoki S, Matsumoto Y, Mizunami M (2006) Roles of octopaminergic and dopaminergic neurons in mediating reward and punishment signals in insect visual learning. Eur J Neurosci 24:2031-2038.

van Swinderen B (2007) Attention-like processes in Drosophila require short-term memory genes. Science 315:1590-1593.

Vergoz V, Roussel E, Sandoz JC, Giurfa M (2007) Aversive learning in honeybees revealed by the olfactory conditioning of the sting extension reflex. PLoS ONE. 2:e288.

Vosshall LB, Stocker RF (2007) Molecular architecture of smell and taste in Drosophila. Annu Rev Neurosci 30:505-533.
Waddell S, Armstrong JD, Kitamoto T, Kaiser K, Quinn WG (2000) The amnesiac gene product is expressed in two neurons in the Drosophila brain that are critical for memory. Cell 103:805-813.

Wu Z, Gong Z, Feng C, Guo A (2000) An emergent mechanism of selective visual attention in Drosophila. Biol Cybern 82:61-68.

Yang MY, Armstrong JD, Vilinsky I, Strausfeld NJ, Kaiser K (1995) Subdivision of the Drosophila mushroom bodies by enhancer-trap expression patterns. Neuron 15:45-54.

Yin JC, Wallach JS, Del Vecchio M, Wilder EL, Zhou H, Quinn WG, Tully T (1994) Induction of a dominant negative CREB transgene specifically blocks long-term memory in Drosophila. Cell 79:49-58.

Yu D, Ponomarev A, Davis RL (2004) Altered representation of the spatial code for odors after olfactory classical conditioning; memory trace formation by synaptic recruitment. Neuron 42:437-449.

Yu D, Keene AC, Srivatsan A, Waddell S, Davis RL (2005) Drosophila DPM neurons form a delayed and branch-specific memory trace after olfactory classical conditioning. Cell 123:945-957.

Zhang K, Guo JZ, Peng Y, Xi W, Guo A (2007) Dopamine-mushroom body circuit regulates saliency-based decision-making in Drosophila. Science 316:1901-1904. 